\title{
Estimation of Experimental Errors Using Monte Carlo Analysis in the Intro- ductory Electrical Circuits Laboratory
}

\section{Dr. Shaghayegh Abbasi, University of San Diego}

Shaghayegh Abbasi received her Ph.D. in Electrical Engineering from University of Washington in 2011. In her thesis, titled 'Integrating top-down and bottom-up nanomanufacturing: Controlling the growth and composition of seeded nanostructures', an innovative nanomanufacturing method is explored and optimized. Upon graduation, she started her career as Senior System Design Engineer at Lumedyne Technologies. She worked on design, simulation, and testing of a Time Domain Switched (TDS) accelerometer.

Dr. Abbasi joined University of San Diego as an adjunct faculty for Shiley-Marcos School of Engineering in 2014, and is currently a full-time faculty at University of San Diego. She is also doing collaborative research with Bioengineering Department at University of California, San Diego on data analysis of glucose sensors for diabetic patients.

\section{Dr. Ernest M. Kim, University of San Diego}

Ernie Kim received his BSEE from the University of Hawaii at Manoa, and MSEE and PhD in Electrical Engineering from New Mexico State University. He has been an electronics engineer at the National Bureau of Standards (now NIST) at the Boulder CO labs where he performed research on precision optical fiber metrology, staff engineer with the Advanced Systems Group of Burroughs Corporation, Manager of Electro-Optics at Ipitek Corporation where he developed early fiber optic CATV systems. Dr. Kim has worked at a number of start-up companies in fiber optic transmission including All Optical Networks, and Lightwave Solutions in San Diego. He joined the University of San Diego Department of Electrical Engineering in 1990. Dr. Kim is a licensed Professional Engineer (EE), and regularly teaches FE and PE exam review courses.

\section{Dr. Thomas F. Schubert Jr. P.E., University of San Diego}

Thomas F. Schubert, Jr. received his B.S., M.S., and Ph.D. degrees in electrical engineering from the University of California, Irvine. He is currently a Professor of electrical engineering at the University of San Diego, San Diego, CA and came there as a founding member of the engineering faculty in $1987 . \mathrm{He}$ previously served on the electrical engineering faculty at the University of Portland, and Portland State University, and on the engineering staff at Hughes Aircraft Company. Prof. Schubert is a member of ASEE and IEEE and is a registered professional engineer in Oregon. He is the 2012 winner of the ASEE Robert G. Quinn award for excellence in engineering education. 


\title{
Estimation of Experimental Errors Using Monte Carlo Analysis in the Introductory Electrical Circuits Laboratory
}

\author{
Shaghayegh Abbasi ${ }^{1, *}$, Ernest M. Kim ${ }^{1}$, and Thomas F. Schubert ${ }^{1}$ \\ ${ }^{1}$ Shiley-Marcos School of Engineering, University of San Diego, San Diego, CA
}

\begin{abstract}
It is a challenge at times to include probability and statistics in electrical engineering courses. In this student experience, experimental data was compared to statistical analysis in an Introductory Electrical Circuits Laboratory Experiment.
\end{abstract}

Experimental data often are used to supplement engineering analysis as a basis for design. Not all data are equally good: errors are a part of every engineering experiment. Gross errors and statistical errors comprise the two major groups of experimental error. Gross errors are due to mistakes made by the humans that conduct the experiments and tests. An example of a gross error is reading the incorrect scale on a meter. Statistical errors are due to randomness in measurement processes, component values, and equipment inaccuracies.

The goal of this experiment in the Introductory Electrical Circuits laboratory was to estimate the uncertainty in experimental measurements and calculated results due to random errors. Single resistor variations in DC electric circuits was used to determine variable uncertainty intervals. The data was used to determine errors in variable values and their effect on measured quantities. Each group's measured values were recorded and histograms of those values were plotted. They were then compared to the data collected by the entire laboratory section and composite histograms produced. Experimental results were then compared to the results of a MultiSim Monte Carlo circuit simulation.

This paper presents the laboratory experiment and procedure, results of student experiments, and assessment of student learning in this required sophomore engineering class and laboratory.

\section{Introduction}

Experimental data often are used to supplement engineering analysis as a basis for design. Lower level engineering students are typically not aware that not all data are equally good and that errors are a part of every engineering experiment [1]. Gross errors and statistical errors comprise the two major groups of experimental error. Gross errors are due to mistakes made by the humans that conduct the experiments and tests. An example of a gross error is reading the incorrect scale on a meter. Statistical errors are due to randomness in measurement processes, component values, and equipment inaccuracies [2].

Statistical error can be further subdivided into fixed errors and random errors. Fixed (or systematic) error causes repeated measurements to be in error by the same amount for each trial and can be removed by proper calibration or correction. Random error (non-repeatability) is different for every reading and therefore cannot be removed. The factors that introduce random error are uncertain by their nature. The objective of

\footnotetext{
*Email Address: sabbasi@sandiego.edu
} 
error analysis is to estimate the probable effect of random errors in experimental results. Such error analysis can be performed either analytically or through simulations methods [3][4].

A number of studies have investigated the use of Monte Carlo simulation in undergraduate level courses [4-7]. These studies apply Monte Carlo analysis in a variety of courses from electronics $[4,5]$ to electromagnetics [6]. The circuits used in these studies are mainly for higher level (junior and senior level) courses. In addition, the studies focus primarily on the Monte Carlo simulation method without experimental comparison.

In this paper a simple laboratory exercise was devised for sophomore-level engineering students in a basic Electrical Circuits course. multiple data readings were taken on the same electrical circuit, both by individual laboratory groups and by multiple laboratory groups, and the variation in results was compared to Monte Carlo analysis of the circuit using Multisim.

In order to judge the efficacy of this experiment to help students understand experimental errors, the students completed anonymous short survey instruments before and after the laboratory exercise. The change in group statistics was tabulated along with individual incremental changes. Results show this exercise to be beneficial for the students.

\section{Experimental Goals}

The goal of the student exercise is to estimate the uncertainty in experimental measurements and calculated results due to random errors in the introductory electrical circuits class. It is assumed that experimental procedures and proper instrument calibration have eliminated fixed errors so that only random errors remain. Of concern in statistical analysis when there is limited time is the size of the sample. One way to increase data sample size was to compare results with other laboratory teams in the class session. Results from each team were presented to the whole class and the overall statistical results derived for the experiment.

Students were given the following information:

The procedure for estimating this uncertainty has two steps:

1. Estimate the uncertainty interval for each variable quantity

2. Analyze the propagation of uncertainty.

Step 1. Estimate the variable uncertainty interval: For many electronic components, manufacturers supply this information. For example, resistor value tolerances are specified by their color code (i.e., $\pm 5 \%$ ). When that information is not given, estimation is trickier. In the case of instrument readings or settings, a reasonable estimate is often \pm half the smallest scale division or, in the case of a meter, \pm half the last unchanging digit.

Step 2. Analyze the propagation of uncertainty: Errors in variable values have a direct effect on measured quantities. Consider a simple series connected resistor consisting of three resistors and a voltage source connected (Figure 1).

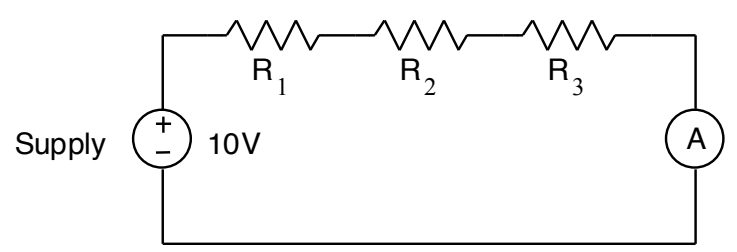

Figure 1. Series Connected Resistor Circuit 


\section{A. The Experiment}

- Connect the circuit of Figure 1. Use the following values for the resistors: $\mathrm{R}_{1}=10 \Omega, \mathrm{R}_{2}=15 \Omega, \mathrm{R}_{3}=27 \Omega$.

- Using a DMM, accurately measure the voltage across the power supply, the three resistors, and the ammeter.

- Calculate, using Ohm's Law, the value of the current in each of the resistors. Compare the results of these calculations to the reading in the ammeter - comment on the findings.

- The ammeter has an equivalent internal resistance (the ratio of the voltage across it to the current through it): find the value of the internal resistance for the ammeter.

- Add the voltages across the resistors (remember polarity is important!) to the voltage across the ammeter - is the result the same as the supply voltage?

\section{B. Error Estimation}

- For the circuit shown in Figure 1, measure the current in the circuit using the ammeter.

- Collect 5 additional $15 \Omega$ resistors. One at a time, replace the original $15 \Omega$ resistor with another $15 \Omega$ resistor and repeat the current measurements. Calculate and record the mean and standard deviation of these measurements.

- Compile all current measurement data from other groups and create a histogram of the measured current value.

- How does the data compare to that of the entire class?

- Use Multisim to simulate the same process using Monte Carlo Analysis and single resistor variation. Compare simulation results to experimental data. Detailed steps on performing Monte
Carlo Analysis in Multisim are as follows:

- Click on the resistor $\mathrm{R}_{1}$ to access its properties and set its tolerance to $5 \%$. Set all other resistors to $0 \%$ tolerance.

- Perform a Monte Carlo analysis in Multisim by selecting the Simulate menu and the Analysis sub-menu, and then Monte Carlo. In the Montel Carlo simulation menu, select DC Operating Point and number of runs (in this experiment it is 5 runs).

\section{Assessment}

In the Spring semester of 2018, 52 students enrolled in the sophomore level electrical circuits laboratory sections completed the lab assessment. Preliminary student assessment of the student perceptions and understanding of Monte Carlo Analysis as applied to electrical circuits is summarized here.

The primary aim of this study was to assess student understanding of component variation in an electrical circuits laboratory experiment. The assessment was completed by entire sections of the laboratory component of the electrical circuits course to assess their understanding of component variation in electrical circuits.

Short questionnaires were designed to provide insight into the student level of knowledge and confidence in the circuit theory and experimental design for the assigned lab experiment for the students. At the beginning of each lab, students were asked to score (on a scale from 1 to 5 ) their prior knowledge. To provide further insight into actual student knowledge level, students were asked to respond with a short answer to the knowledge questions. After the design exercise was completed, the questionnaires were again completed by the students and the post- 
exercise written responses were used to measure changes in knowledge level. In order to track individual student incremental changes, the surveys were stapled together by each student thereby preserving student anonymity. The use of student-assigned scores to assess gains in student knowledge and confidence has been successfully used by the investigator team in previous studies by Schubert, et. al. [8][9].

The following four questions concerning knowledge on voltage and current measurements, as well as Monte Carlo error estimation method were asked before and after the lab exercise:

1. What is a good way to measure resistance value?

2. When measuring voltage across or current through a resistor, what instrument would you use?

3. How should power absorbed by a resistor be measured or calculated?

4. What is the Monte Carlo Method?

The knowledge score was based on the following scale:

$1=$ No Clue, I have no idea if I can apply the concept.

2 = Low, I have heard of the concept, but have little confidence that I can apply it.

$3=$ Moderate, I think I understand the concept, but am unsure about applying it.

4 = High, I am fairly sure I understand the concept and am fairly sure I can apply it.

$5=$ Superb, I am very confident that I understand the concept and can apply it to a new problem.

The results of the Spring 2018 confidence survey using Monte Carlo methods follow. Two-tailed T-tests were run on the paired sets of data (pre and post). In all cases the change in mean was determined to be significant: the probability that the means were alike was less than 0.00015 in all cases.

What is a good way to measure resistance values? Change in mean +0.94

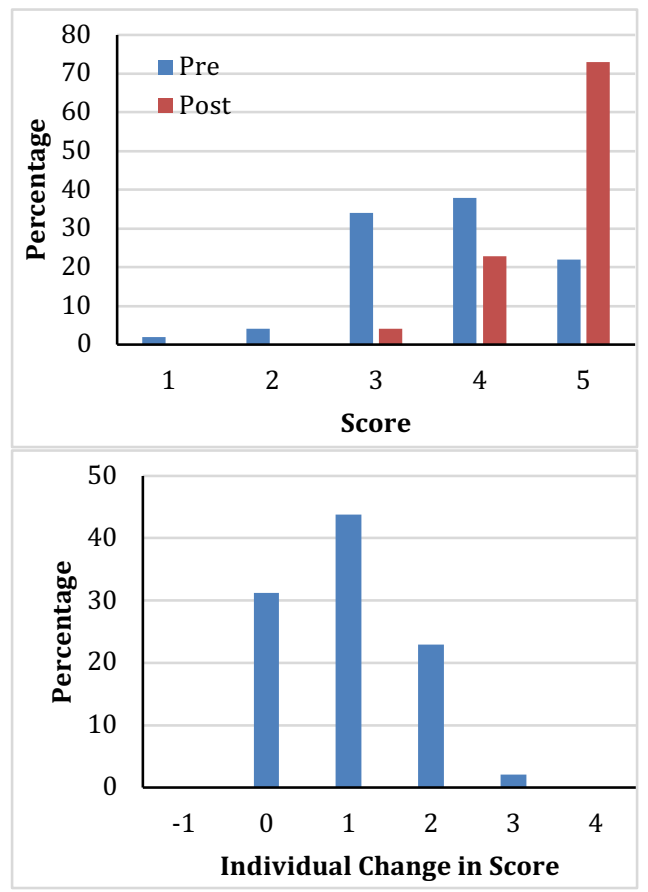

When measuring voltage across or current through a resistor, what instrument would you use? Change in mean +0.61
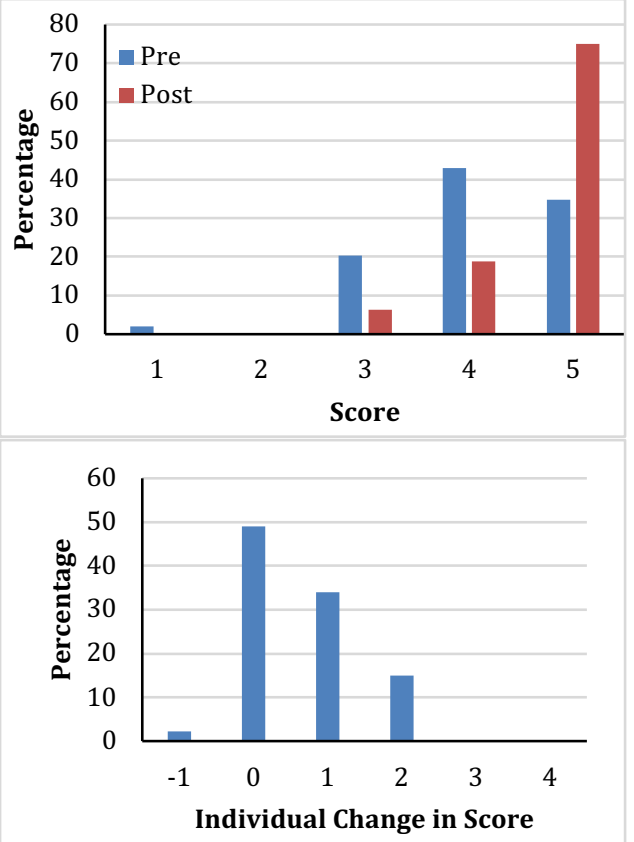
How should power absorbed be measured or calculated? Change in mean +0.86
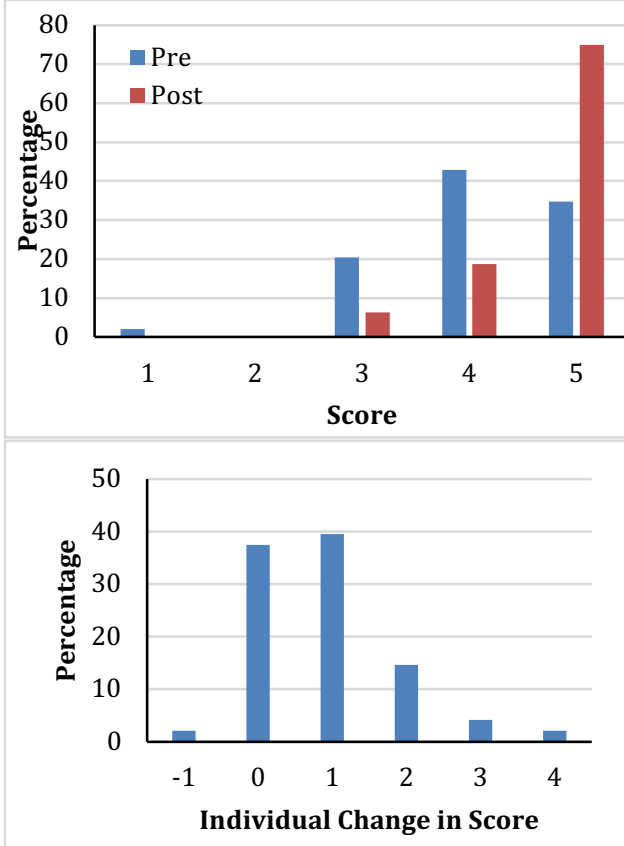

What is the Monte Carlo Method?

Change in mean +1.10
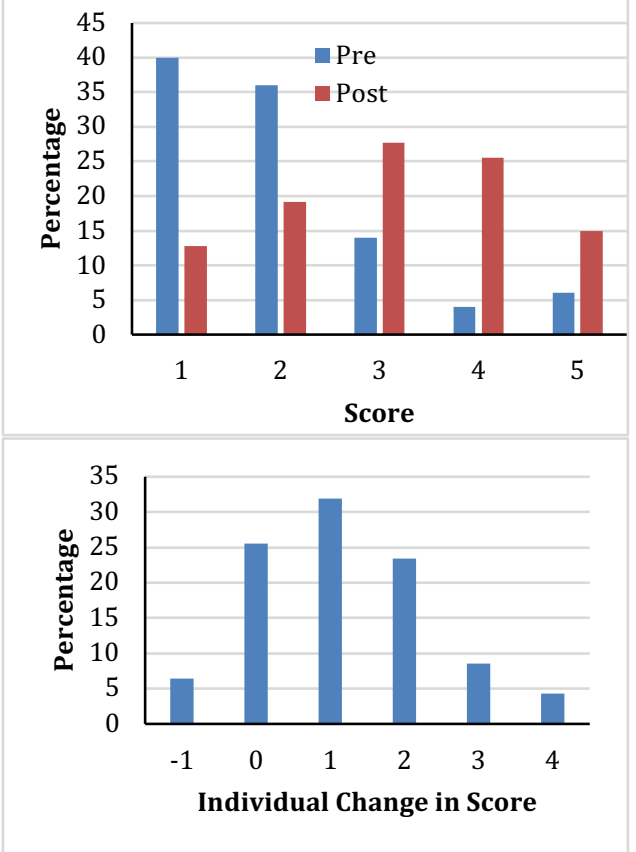

Another portion of the questionnaire was designed to assess student confidence concerning applying measurement and Monte Carlo methods before and after the lab exercise:
1. I can measure Resistance values.

2. I can measure voltages and currents.

3. I can use Ohm's Law.

4. I can determine resistor power absorption.

5. I can find the mean of sampled data values.

6. I can find the standard deviation of sampled data values.

7. I can apply Monte Carlo methods to determine the variable uncertainty interval.

The confidence score was based on the following scale:

$1=$ No clue, this concept is new to me.

2 = Low, I have only heard about the concept.

3 = Moderate, I know about the concept, but have not applied it.

$4=$ High, I know the concept and have tried it. $5=$ Superb, I know the concept and have successfully applied it.

The distribution of students' answers on their confidence before and after the exercise for Spring 2018 are shown below.

\section{I can measure resistance values.}

Change in mean +0.83
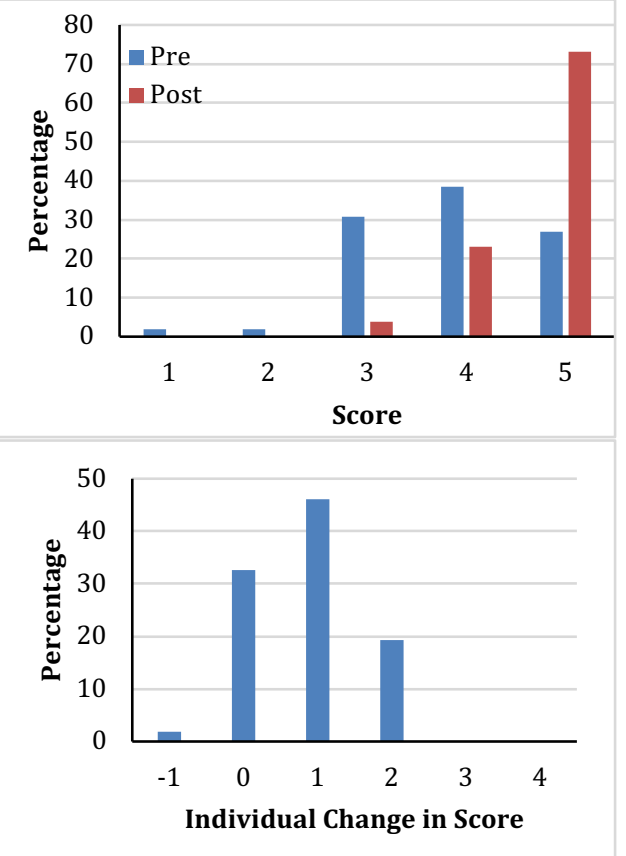
I can measure voltages and currents. Change in mean +0.77
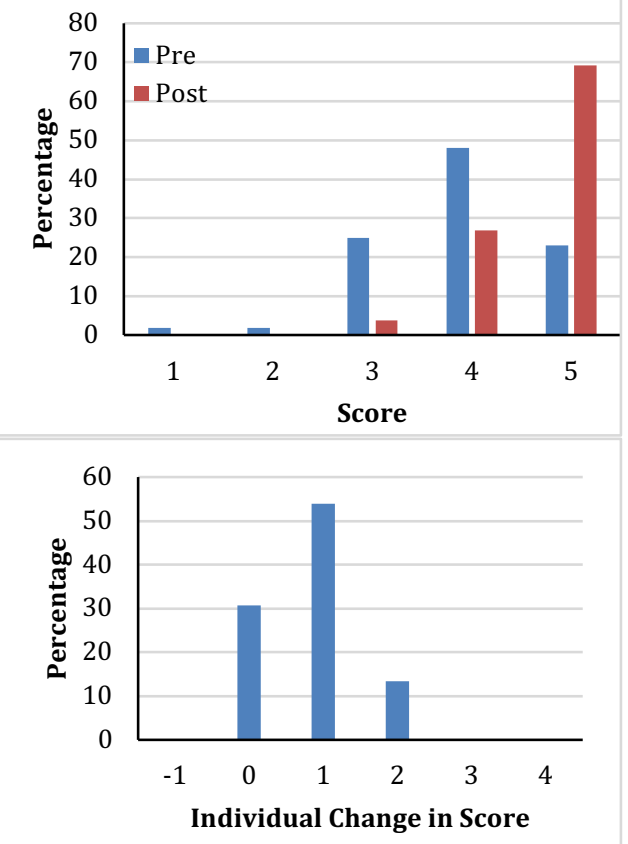

I can use Ohm's Law.

Change in mean +0.58
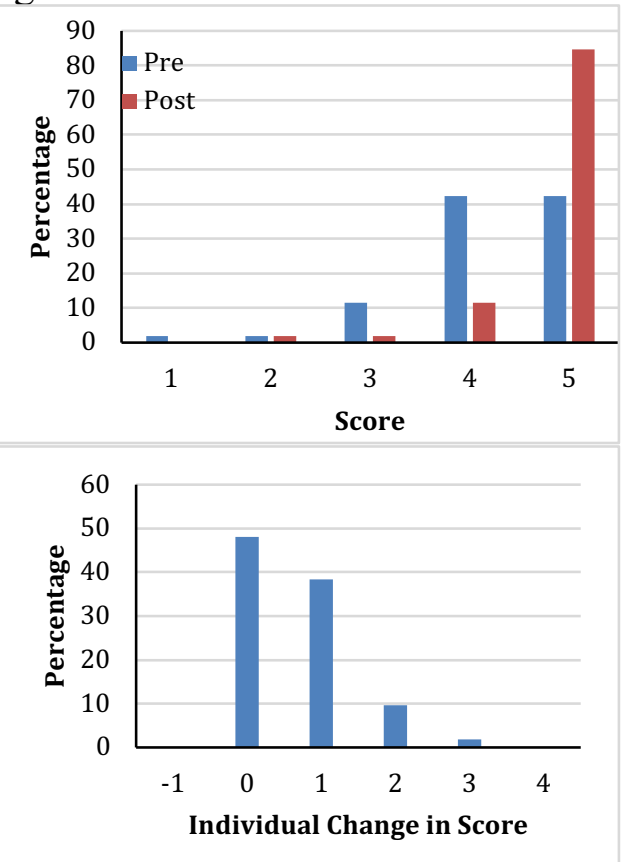

I can determine resistor power absorption. Change in mean +1.15
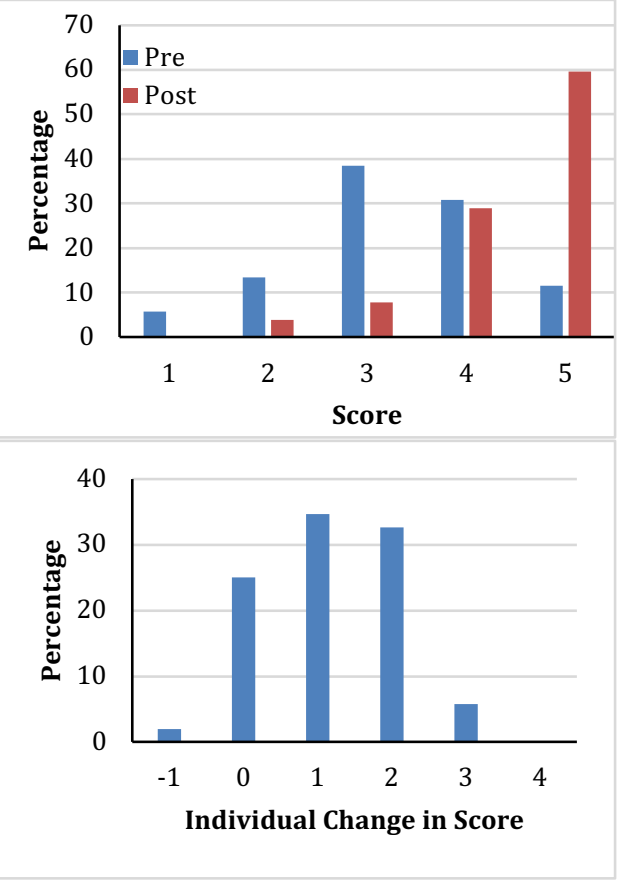

I can find the mean of sampled date values. Change in mean +0.44
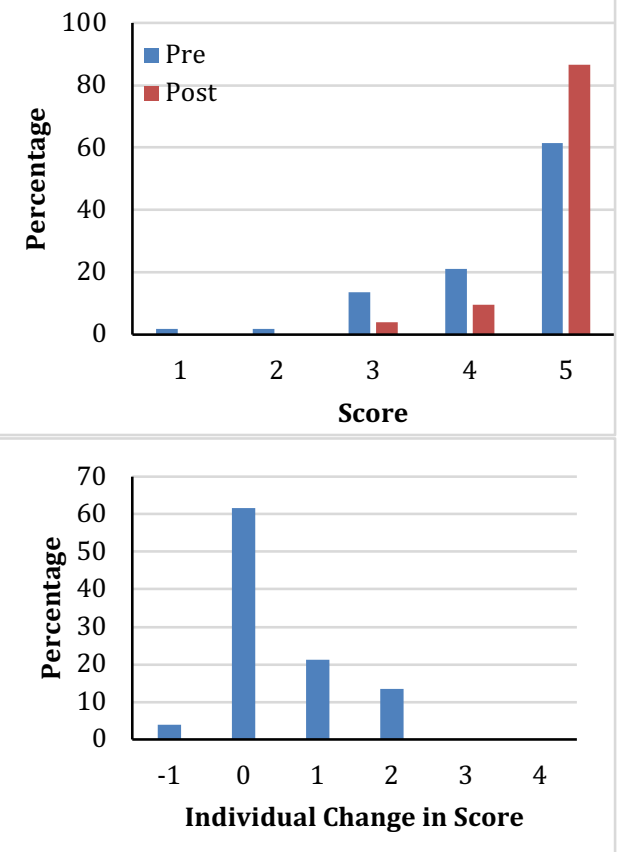
I can find the standard deviation of sampled data values. Change in mean +0.60

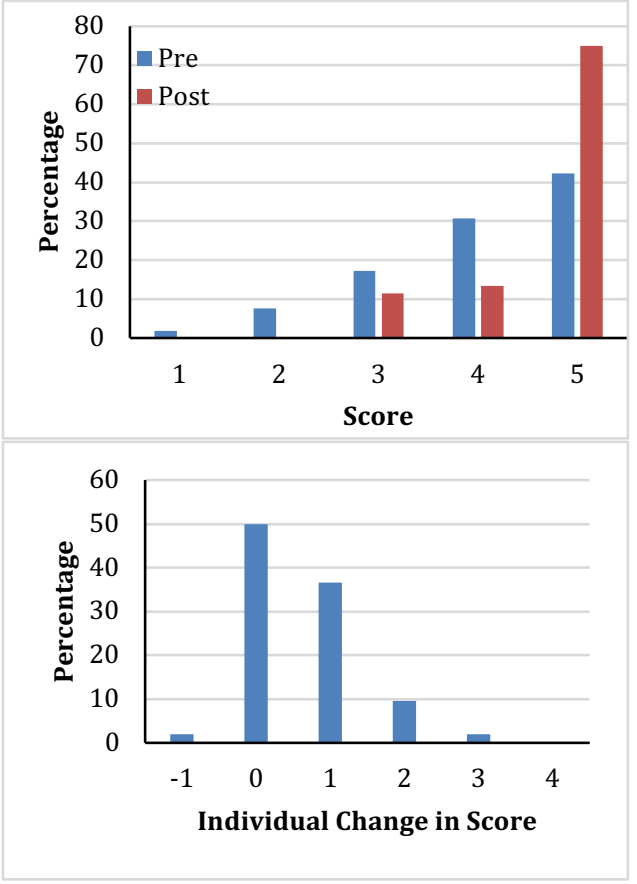

I can apply Monte Carlo Methods to determine the variable uncertainty.

Change in mean +0.74
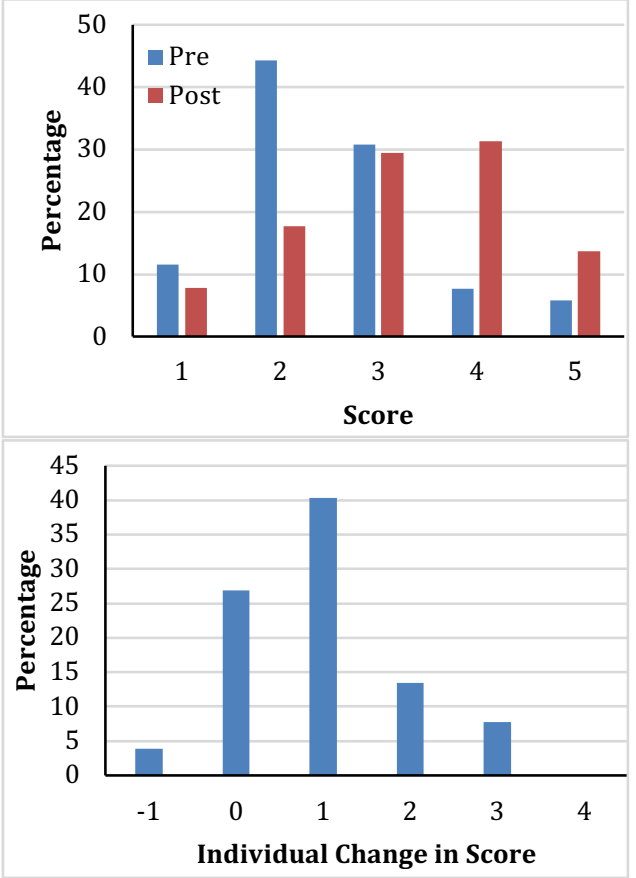

\section{Summary}

The use of Monte Carlo method in an introductory electrical engineering laboratory course to introduce students to statistical variance was studied.

Table 1 displays the change in mean for different knowledge and skills questions before and after the lab session. It is evident that there has been an increase in knowledge and skill of students after the experiments, including understanding of the Monte Carlo analysis. In some areas students have greater prior knowledge, hence the increase in score is less significant. For instance, "I can find the mean of sampled data values" had an average increment of +0.44 . On the other hand, in other areas which are new to students the lab session contributed greatly to student learning. This can be observed for instance in "What is the Monte Carlo Method?" question, where an increment of +1.1 is recorded.

\begin{tabular}{|l|l|}
\hline Survey Question & \multicolumn{1}{|c|}{$\begin{array}{l}\text { Average Change } \\
\text { in Score }\end{array}$} \\
\begin{tabular}{|l|l|} 
What is a good way to measure & +0.94 \\
resistance value?
\end{tabular} & \\
\hline $\begin{array}{l}\text { When measuring voltage across } \\
\text { or current through a resistor, } \\
\text { what instrument would you use? }\end{array}$ & +0.61 \\
$\begin{array}{l}\text { How should power absorbed by } \\
\text { a resistor be measured or } \\
\text { calculated? }\end{array}$ & +0.86 \\
\hline $\begin{array}{l}\text { What is the Monte Carlo } \\
\text { Method? }\end{array}$ & +1.10 \\
\hline I can measure Resistance values. & +0.83 \\
\hline $\begin{array}{l}\text { I can measure voltages and } \\
\text { currents. }\end{array}$ & +0.77 \\
\hline I can use Ohm's Law. & +0.58 \\
\hline $\begin{array}{l}\text { I can determine resistor power } \\
\text { absorption. }\end{array}$ & +1.15 \\
\hline $\begin{array}{l}\text { I can find the mean of sampled } \\
\text { data values. }\end{array}$ & +0.44 \\
\hline $\begin{array}{l}\text { I can find the standard deviation } \\
\text { of sampled data values. }\end{array}$ & +0.60 \\
\hline $\begin{array}{l}\text { I can apply Monte Carlo } \\
\text { methods to determine the } \\
\text { variable uncertainty interval. }\end{array}$ & +0.74 \\
\hline $\begin{array}{l}\text { Table 1: Summary of survey results demonstrating } \\
\text { score improvement in basic knowledge and skill on } \\
\text { electrical measurements and Monte Carlo analysis. }\end{array}$ \\
\hline
\end{tabular}


Summary scores for students' knowledge before a laboratory exercise was an average of 3.3 with a standard deviation of 1.1 . The summary score after the exercise was an average of 4.6 with a standard deviation of 0.66 resulting in overall modest increase in knowledge.

The overall increase of +0.74 in level of confidence that students had with applying Monte Carlo Methods indicates that they gained knowledge and understanding of the Monte Carlo method for circuit component variation as a result of this laboratory experiment.

\section{References}

[1] C. Greco, J. D. Reasoner, Jr., D. Bullock, C. L. Cstillo, P., S. Buford, and g. g. Richards, "Efficacy of Lab Reports for Electrical Circuits Laboratory Assessment," Proceedings of the Annual Conference of he American Society of Engineering Education, 2011.

[2] R. Du, M. A. Butkus, and J. A. Starke, "Incorporating Risk and Uncertainty into Undergraduate Environmental Engineering Curricula", Proceedings of the Annual Conference of he American Society of Engineering Education, 2016.

[3] R.J. Distler, "Monte Carlo Analysis of System Tolerance", IEEE Transactions on Education, Volume 20 (2), 1977.
[4] J.C. Hamann, J.W. Pierre, S.F. Legowski, and F.M. Long, "Using Monte Carlo Simulations to Introduce Tolerance Design to Undergraduates", IEEE Transactions on Education, Volume 42 (1), 1999.

[5] J. A. Svoboda, "Using spreadsheets in introductory EE courses," IEEE Transactions on Education, Volume 35, pp. 226-229, 1992.

[6] M. N. O. Sadiku, "Monte Carlo methods in an introductory electromagnetic course," IEEE Transactions on Education, Volume 33, pp. 73-80, 1990.

[7] H. McWilliams, "Utilization of Monte Carlo and worst-case computer simulation methods for evaluation of electronic circuit designs", Computer Education Journal, Volume II(3), pp. 17-20, 1992.

[8] Thomas F. Schubert, Jr., Frank G. Jacobitz, and Ernest M. Kim, "The Engineering Design Process: An Assessment of Student Perceptions and Learning at the Freshmen Level", Proceedings of the 2009 ASEE Annual Conference \& Exposition, Austin, TX, June 14-17, CD-ROM, 2009.

[9] Thomas F. Schubert, Jr., Frank G. Jacobitz, and Ernest M. Kim, "Exploring Three-Phase Systems and Synchronous Motors: A Low-Voltage and Low-Cost Experiment at the Sophomore Level", IEEE Transactions on Education, pp. 67-76, vol. 54, no. 1, February 2, 2011. 